\title{
Modelo experimental de doença pleural maligna induzida por células LLC (Lewis Lung Carcinoma)
}

\author{
Pedro Henrique Shimiti Hashizume', Milena Marques Pagliarelli Acencio², \\ Lisete Ribeiro Teixeira ${ }^{2}$
}

Hashizume PHS, Acencio MMP, Teixeira LR. Modelo experimental de doença pleural maligna induzida por célula LLC (Lewis Lung Carcinoma). Rev Med (São Paulo). 2015 jan,-mar.;94(1):63-4.

\section{INTRODUÇÃO}

Derrame pleural maligno (DPM) é um fator de mau prognóstico em pacientes com câncer de pulmão avançado. Sua patogênese ainda é pouco compreendida e as opções terapêuticas são limitadas. Modelos animais de DPM podem demonstrar novos aspectos fisiopatológicos desta doença. Stathopoulos et al. em 2006 (Am J Respir Cell Mol Biol. 2006;34:142-50) descreveram um modelo de DPM com 1,5 x105 células de LLC injetadas diretamente no espaço pleural de camundongos. Os autores relataram carcinomatose com derrame pleural, tumores pleurais e $100 \%$ de mortalidade após 17 dias.

\section{OBJETIVO}

Estabelecer um modelo de DPM em camundongo com células de adenocarcinoma de pulmão (LLC) que promova a doença, porém com maior tempo de sobrevivência objetivando futuras investigações em patogênese e terapia.

\section{METODOLOGIA}

Este estudo foi aprovado pelo comitê de ética (CAPPesq) sob o número 0628/09. Sessenta camundongos C57/BL6 foram divididos em grupos que receberam injeções intrapleural de 0,1, 0,5 ou 1,5 x 105 células de LLC. Trinta animais foram acompanhados até a morte para o estabelecimento de curva de sobrevida. Trinta camundongos foram submetidos à eutanásia aos 7, 14 e 21 dias e avaliados nos diferentes tempos: peso, mobilidade (escore 0-3), presença do tumor na pleura visceral e pericárdio (escore $0-4$ ), células inflamatórias em parênquima pulmonar e alterações histológicas em rim, fígado e baço (escore 0-4). Análise estatística: One Way ANOVA, Curva de Kaplan -Meier, $\mathrm{p}<0,05$.

\section{RESULTADOS}

Observou-se o menor tempo de sobrevivência no grupo que recebeu a maior concentração de células LLC $(\mathrm{p}<0,05 ; 1,5 \times 105=21$ dias, $0,5 \times 105=26$ dias e $0,1 \times 105=28$ dias). Vinte e um dias após a injeção intrapleural de células LLC, uma significativa redução de peso foi observado no grupo de 1,5 x 105 células (p $<0,05)$. A diminuição de mobilidade foi mais evidente na maior concentração. Presença de tumor na pleura visceral foi observada em todos os grupos e proporcional à concentração e tempo desde a instilação de células LLC

\footnotetext{
$1^{\circ}$ lugar Prêmio Painéis - Área Básica no 33 COMU - Congresso Médico Universitário da FMUSP, SP, 31 de out. a 02 de nov. de 2014. 1. Acadêmico de Medicina da Faculdade de Medicina da Universidade de São Paulo.

2. Orientadores, Faculdade de Medicina da Universidade de São Paulo.
} 
$(\mathrm{p}<0,05)$. Metástase em pericárdio foi mais evidente na concentração de 1,5 x 105 células. As células inflamatórias do parênquima pulmonar e as alterações histológicas nos rins, fígado e baço foram observados em todos os grupos com os maiores escores nos grupos de $0,5 \times 105$ e $1,5 \times$ 105 células.

\section{DISCUSSÃO E CONCLUSÕES}

O modelo de câncer de pulmão em camundongos foi efetivamente estabelecido pela injeção de $0,5 \times 105$ células de LLC na cavidade pleural, expressando alterações neoplásicas semelhantes às relatadas anteriormente, mas com um aumento significativo no tempo de sobrevivência. Este modelo poderá proporcionar observações dinâmicas do comportamento biológico das células tumorais na cavidade pleural e ser promissor na investigação sobre o câncer de pulmão avançado, bem como na utilização de terapias alvo antitumorais. 